\title{
Effects of Dangguibuxue Tang, a Chinese herbal medicine, on growth performance and immune responses in broiler chicks
}

\author{
Xu Ting Li,* Bin Wang, Jin Liang Li, Rui Yang, Si Cong Li, Min Zhang, Wei Huang and Liang Cao \\ Institute of Veterinary Pharmacology, Sichuan Animal Science Academy, Chengdu, Sichuan 610066, China
}

\begin{abstract}
The effects of Dangguibuxue Tang (DBT) on growth performance and immunity response in immunosuppressed broiler chicks were investigated in this study. 240 one-d-old broiler chicks (DaHeng S01) were randomly divided into 4 groups, 2.0\% DBT-treatment (A), 0.5\% DBT-treatment (B), cyclophosphamide-control (C), and control group (D). From $4 \mathrm{~d}$ to $7 \mathrm{~d}$ of age, chicks in group A, B and C were given cyclophosphamide (CY) at a dosage of $100 \mathrm{mg} / \mathrm{kg}$ body weight (BW) daily by intraperitoneal injection to induce immunosuppression. Chicks in group D were given an equal volume of physiological saline daily by intraperitoneal injection and considered normal chicks. Groups A and B were supplemented with $2.0 \%$ or $0.5 \%$ of DBT in the drinking water from $8 \mathrm{~d}$ to $42 \mathrm{~d}$ of age. Groups C and D did not receive any additional medication. The results revealed that chicks from group B had lower feed:gain rate (FGR), lower total mortality, higher immunity organ indexes, higher levels of Newcastle disease (ND) antibody and infectious bursal disease (IBD) antibody, higher interleukin-2 and interleukin-6 levels, and greater lymphocyte proliferative responses to concanavalin A (ConA) during the experiment than those from group C. However, no significant difference in the immunity status in the two levels of DBT-treatment was observed. These results indicate that supplementation of $0.5 \%$ of DBT can improve both cellular immunity and humoral immunity in immunosuppressed broiler chicks.
\end{abstract}

Key words: Dangguibuxue Tang, growth performance, immune, chick.

\section{INTRODUCTION}

In the poultry industry, broiler chicks can be exposed to stressors and infectious diseases that impair innate and acquired immunity. Infectious bursal disease (IBD), Newcastle disease (ND), chicken infectious anemia (CIA), and Marek's disease (MD) are major infectious diseases that interfere with acquired vaccinal immunity (Horre, 2011). Moreover, some noninfectious factors such as heat stress and aflatoxin also impair immunity functions (Yarru et al., 2009; Han et al., 2010; Hoerr, 2010). Generally, vaccines and antibiotics are used for controlling these diseases. However, vaccines have been shown to provoke poor immune responses due to vaccine failure sometimes (Liu et al., 2008). On the other hand, the extensive use of antibiotics for controlling secondary infections in animal production leads to a variety of problems such as development of drug-resistant animals and drug residues in the products (Diarrassouba et al., 2007). Therefore, the use of immunomodulators to improve the immune function in broiler chicks has been considered to be an efficient means of improving performance in the poultry industry (Hernández et al., 2004; Willis et al., 2007).

Natural medicine products have been widely used as food supplements for farm animals in China for centuries, and show many bioactivities such as antimicrobial activity, immune enhancement and stress reduction. Dangguibuxue Tang (DBT), a Chinese medicinal decoction that contains Angelicae sinensis radix (Danggui) and Astragaus radix (Huangqi) at a ratio of 1:5, has been widely used in China for more than 800 years. Pharmacological results indicated that DBT has the abilities to promote hematopoietic functions (Ning et al., 2002) and modulate immune functions: to stimulate cardiovascular circulation (Zheng et al., 2011); to prevent osteoporosis (Choi et al., 2011), to increase anti-oxidation activity (Zheng et al., 2011), to stimulate immune response (Gao et al., 2007; Liu at el., 2011; Hsieh et al., 2003) and modulate the lymphocyte activity of cancer patients after chemotherapy and radiotherapy (Hsieh et al., 2003; Zhang et al., 2006). Although research interest has been focused on DBT immunomodulating properties that may be useful in promoting growth performance and immunity in animals, the effects of DBT on growth performance and immune functions in chicks have not been investigated.

This study was conducted to investigate the effects of DBT on growth performance and the immune responses of immunosuppressed broiler chicks induced by cyclophosphamide (CY) treatment.

\section{MATERIALS AND METHODS}

Animals

A total of 240 1-day-old female broiler chicks (DaHeng S01, DaHeng Poultry breeding company, Sichuan, China) were randomly divided into 4 groups (A to D). Each group was composed of five replicate cages with twelve chicks each. The environmental temperature was controlled and gradually reduced from 36 to $22{ }^{\circ} \mathrm{C}$ until the end of the experiment. The lighting program was $24 \mathrm{~h}$ light throughout the experiments. Fresh food and water were provided daily and were available ad libitum. The basal diet was a commercial-type corn-soybean meal diet formulated to meet or exceed the nutritional requirements of growing chicks as recommended by the NRC (1994). 


\section{Experimental design}

The methodology used for establishing the immunosuppressed chick model was described by Munir et al. (2009) and Kim et al. (2004), with minor modifications. Briefly, from $4 \mathrm{~d}$ to $7 \mathrm{~d}$ of age, chicks in group $\mathrm{A}, \mathrm{B}$ and $\mathrm{C}$ were given cyclophosphamide (CY) at a dosage of $100 \mathrm{mg} / \mathrm{kg}$ body weight (BW) daily by intraperitoneal injection to induce immunosuppression. Chicks in group $\mathrm{D}$ were given an equal volume of physiological saline daily by intraperitoneal injection and considered normal chicks. From $8 \mathrm{~d}$ to $42 \mathrm{~d}$ of age, chicks in groups $\mathrm{A}$ and B were supplemented with $2.0 \%$ or $0.5 \%$ of DBT in the drinking water and served as 2.0\% DBT-treatment and 0.5\% DBT-treatments, respectively; groups $\mathrm{C}$ and $\mathrm{D}$ were not supplemented with any additional medication and served as CY-control and normal group, respectively.

Chicks in all groups received a live Newcastle disease vaccine (LaSota strain, Guangxi LiYuan Biological Co., Lit.) via eye drop on day 1 and 7 , and received a live infectious bursal disease vaccine (Strain D-78, Bestar Laboratories Singapore Pte. Ltd.) via eye drop at $14 \mathrm{~d}$ of age. At the $28 \mathrm{~d}$ of age, all chicks were injected intramuscularly with $0.2 \mathrm{~mL}$ (per chick) inactivated Newcastle disease vaccine (LaSota strain, Hile Biological Co., Lit.).

The experiment was performed in accordance with animal welfare principles and was conducted under protocols approved by the Sichuan Animal Science Academy.

\section{DBT preparation}

Angelicae sinensis radix (Danggui) and Astragalus radix (Huangqi) were purchased from DERENTANG Group Co., Ltd., Chengdu, China. DBT contained Angelicae sinensis radix (Danggui) and Astragalus radix (Huangqi) at a ratio of 1:5. The crude material $(10 \mathrm{~kg})$ was extracted twice with $30 \%$ ethanol (with $2 \mathrm{~h}$ reflux) and the extract was then concentrated under reduced pressure. The decoction was filtered, lyophilized, and stored at $4{ }^{\circ} \mathrm{C}$. The yield of dried extract was approximately 25.0\% (w/w). Previous studies (Dong et al., 2006; Gao et al., 2006) have demonstrated that polysaccharides, astragaloside IV and ferulic acid are major active constituents in DBT. In the present study, the levels of ferulic acid, astragaloside IV and polysaccharides were used as chemical markers for the quality control of DBT preparation. The final extract contained 28.5 $\mu \mathrm{g} / \mathrm{g}$ ferulic acid, $253.0 \mu \mathrm{g} / \mathrm{g}$ astragaloside $\mathrm{IV}$ and $46.7 \mathrm{mg} / \mathrm{g}$ polysaccharides.

\section{Sample collection}

The chicks were weighed individually on d 1, 7, 14, 21, 28, 35, and 42. Food intake per cage was measured daily. Average daily gain and feed:gain ration were calculated. Mortality and BW of dead birds were recorded daily.

At 14,28 , and $42 \mathrm{~d}$, twenty chicks (4 chicks per replicate) were randomly selected and weighed after food deprivation for $12 \mathrm{~h}$. Individual blood samples were collected from wing veins into non-heparinized tubes to measure serum ND and IBD antibody titer and serum interleukin (IL-2, IL-6) production. Serum was separated by centrifugation at $400 \times \mathrm{g}$ for $10 \mathrm{~min}$ and stored at $4{ }^{\circ} \mathrm{C}$ until analysis.

In addition, blood samples ( $5 \mathrm{~mL}$ from each chick) were collected directly from the heart in aseptic tubes containing sodium heparin for assay of peripheral lymphocyte proliferation.

After collection of blood samples, all chicks were killed by exsanguination and the spleen, thymus, and bursa of Fabricius were removed immediately and weighed. The immune organ relative weight was calculated using the following formula: immune organ relative weight $=$ immune organ weight $(\mathrm{g}) /$ body weight $(\mathrm{g}) \times 100 \%$.

Measurement of serum ND and IBD antibody titer

Serum ND antibody titer and IBD antibody titer were measured by ELISA using the Newcastle Disease Antibody Test Kit and Infectious Bursal Disease Antibody Test Kit from Shenzhen Lvshiyuan Biotechnology Co., Ltd, respectively. Titers were obtained and calculated as described in the manufacturer's instruction.

Measurement of serum IL-2, IL-6 production

The serum levels of IL- 2 and IL- 6 were measured using the IL-2 ELISA Kit and IL-6 ELISA Kit (CK-E60049C, RapidBiology Laboratory), respectively. The measurements complied strictly with the assay procedure in the manufacturer's manual.

\section{Assay of Peripheral Blood Lymphocyte Proliferation}

A 3-[4,5-dimethylthiazol]-2,5-diphenyltetrazolium bromide (MTT, Sigma Chemical Co., St. Louis, MO) assay was used to determine the peripheral blood lymphocyte proliferation response at 14, 28, and $42 \mathrm{~d}$ of age. This assay was performed according to the procedure described by Munir et al. (2009), with minor modifications. Briefly, $5 \mathrm{~mL}$ of blood samples collected directly from the heart of chicks in aseptic tubes containing sodium heparin and mixed with an equal volume of Hank's solution were layered on lymphocyte separation medium (HaoYang Biological Manufacture Co. Ltd., Tianjin, China). Lymphocytes were isolated after $30 \mathrm{~min}$ and centrifuged at $1000 \times g$. The lymphocyte fraction was collected from the interface and washed 2 times with RPMI 1640 (Invitrogen Corp., Grand Island, NY) incomplete culture medium. Lymphocytes were then resuspended in $2 \mathrm{~mL}$ of RPMI 1640 complete culture medium supplemented with 5\% (vol/vol) fetal calf serum, $0.5 \%$ penicillin (final concentration, $100 \mathrm{U} / \mathrm{mL}$ ), $0.5 \%$ streptomycin (final concentration, 100 $\mu \mathrm{g} / \mathrm{mL}$ ). Cells were detected by trypan blue dye exclusion and counted to adjust the density to $4 \times 10^{6}$ per milliliter of culture medium. Each sample was seeded into 6 wells of a 96-well culture plate, with each well receiving $100 \mu \mathrm{L}$ of cell suspension. Each of the first 3 of 6 wells received $20 \mu \mathrm{L}$ the lymphocyte mitogen concanavalin A (Con A, Sigma Chemical Co.), whereas each of the remaining 3 wells received $20 \mu \mathrm{L}$ of RPMI-1460 medium supplemented with antibiotics. The plates were incubated at $37{ }^{\circ} \mathrm{C}$ with $5 \% \mathrm{CO}_{2}$ in a MCO-18AIC $\mathrm{CO}_{2}$ incubator, (Sanyo Electric Biomedical Co. Ltd., Tokyo, Japan) for $64 \mathrm{~h}$. After incubation, $20 \mu \mathrm{L}$ of $5 \mathrm{mg} / \mathrm{mL}$ MTT was added to each well and the plates were reincubated for $4 \mathrm{~h}$. After incubation, plates were centrifuged at $1000 \times \mathrm{g}$ for $10 \mathrm{~min}$ at room temperature $\left(22{ }^{\circ} \mathrm{C}\right)$, supernatant was discarded and 100 $\mathrm{uL}$ of dimethyl sulfoxide per well was added to solubilize the MTT crystals. Finally, optical density (OD) of cells in each well was measured using an automated ELISA reader (model 550 
Microplate Reader, Bio-Rad Pacific Ltd., Hong Kong, China) at $490 \mathrm{~nm}$. The stimulation index (SI) was calculated as the OD value of mitogen culture divided by the OD of nonstimulated cultures.

\section{Statistical Analysis}

The results were expressed as means or means \pm standard deviation (SD) and all data were statistically analyzed by oneway ANOVA, using SPSS version 13.0 software for Windows (SPSS Inc., Chicago, IL). Differences between treatment groups were tested by Duncan's test, and differences were significant at $P<0.05$.

\section{RESULTS}

\section{Growth Performance}

The effects of DBT on body weight gain, feed:gain rate (FGR) and total mortality are summarized in Table 1.

In general, group $\mathrm{D}$ exhibited better growth performance than groups A, B and C during the experiment. Group D had higher $(\mathrm{P}<0.05)$ body weight, weight gains and food intakes than those of group A, B and C before d 21 (data not shown). At $28 \mathrm{~d}$ of age, there was no significant difference $(P>0.05)$ in body weight between group $C$ and group $D$, but group $D$ had higher $(\mathrm{P}<0.05) \mathrm{BW}$ than groups $\mathrm{A}$ and $\mathrm{B}$. However, groups $\mathrm{A}$ and $\mathrm{B}$ had lower $(\mathrm{P}<0.05)$ FGR than groups $\mathrm{C}$ and $\mathrm{D}(1.87,1.80$ vs. $1.96,1.97$, respectively).

In addition, the total mortality in group $\mathrm{D}(3.3 \%)$, group A $(8.3 \%)$ and group B $(6.7 \%)$ were lower than group C $(16.7 \%)$ during the experiment.

\section{Immune Organ Relative Weight}

Group D had higher $(\mathrm{P}<0.05)$ relative weight of bursa of Fabricius than that of group A, B and C over the experimental period (data not shown). There was a significant $(P<0.05)$ decrease in spleen relative weight in group A $(0.144 \pm 0.015)$, group B $(0.152 \pm 0.013)$ and group C $(0.132 \pm 0.010)$ compared to group D $(0.178 \pm 0.016)$ at $14 \mathrm{~d}$ of age. After $28 \mathrm{~d}$ of age, no significant differences in spleen relative weight in group $\mathrm{A}$, $\mathrm{B}$ and D were observed, whereas a significantly decreased spleen relative weight was observed in group C. In contrast, no significant changes were noted in thymus relative weight among the 4 groups (data not shown).

\section{Serum ND and IBD Antibody Titer}

The effects of DBT on serum ND and IBD antibody titer are shown in Figure 1 and Figure 2. Before $28 \mathrm{~d}$ of age, a gradual decrease of ND antibody titers in all groups was observed. However, groups $\mathrm{A}$ and $\mathrm{B}$ had higher ND antibody titer than group $\mathrm{C}$, especially at $28 \mathrm{~d}$ and $42 \mathrm{~d}$ of age $(\mathrm{P}<0.05)$. No significant difference in the ND antibody titer was observed among groups A, B and D (Figure 1). In addition, group D had higher $(\mathrm{P}<0.05)$ IBD antibody titer than that of groups $\mathrm{A}, \mathrm{B}$ and $\mathrm{C}$ at $\mathrm{d} 28$ of age. At $\mathrm{d} 42$ of age, groups $\mathrm{B}$ and $\mathrm{D}$ had higher $(\mathrm{P}<$ 0.05) IBD antibody titer than that of group C (Figure 2). At d 14 of age, IBD antibody titer was maternal antibody and no significant difference was observed among the 4 groups (Figure 2).

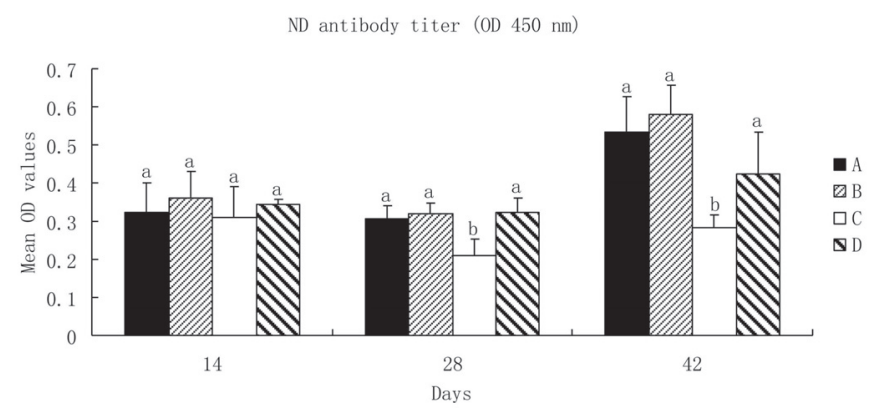

Figure 1. Effects of DBT on Newcastle Disease (ND) antibody titer in chickens ${ }^{1}$

$a, b$ Within the same day, bars with different letters $(a, b)$ differ significantly $(P<0.05) . n=20$. Chicks in all groups received live Newcastle disease vaccine (LaSota strain, Guangxi LiYuan Biological Co., Lit.) at $1 \mathrm{~d}$ and $7 \mathrm{~d}$ of age. At the $28 \mathrm{~d}$ of age, all chicks were injected intramuscularly with $0.2 \mathrm{~mL}$ (per chick) inactivated Newcastle disease vaccine (LaSota strain, Hile Biological Co., Lit.). ELISA antibody titers (means \pm SD) measured from blood samples collected at $14 \mathrm{~d}, 28 \mathrm{~d}$ and $42 \mathrm{~d}$ of age.

${ }^{1} \mathrm{~A}$ : $2.0 \%$ DBT-treatment, treated with $\mathrm{CY}$ and supplemented with $2.0 \%$ DBT; B: $0.5 \%$ DBT-treatment, treated with $\mathrm{CY}$ and supplemented with $0.5 \% \mathrm{DBT} ; \mathrm{C}$ : $\mathrm{CY}$-control, treated with $\mathrm{CY}$ and no medication; D: normal group, no $\mathrm{CY}$ and no medication.

TABLE 1

Effect of DBT on growth performance of broiler chicks (1 to $42 \mathrm{~d}$ )

\begin{tabular}{cccccc}
\hline Item & Period & $\mathbf{A}^{\mathbf{1}}$ & $\mathbf{B}$ & $\mathbf{C}$ & $\mathbf{D}$ \\
\hline Body weight $(\mathrm{g})$ & Initial & $37.1 \pm 1.4$ & $37.6 \pm 1.8$ & $38.2 \pm 1.8$ & $39.1 \pm 1.1$ \\
& $14 \mathrm{~d}$ & $168.7^{\mathrm{b}} \pm 28.3$ & $164.1^{\mathrm{b}} \pm 26.7$ & $163.9^{\mathrm{b}} \pm 31.8$ & $219.4^{\mathrm{a}} \pm 22.6$ \\
& $28 \mathrm{~d}$ & $505.6^{\mathrm{b}} \pm 52.5$ & $512.9^{\mathrm{b}} \pm 54.3$ & $525.4^{\mathrm{a}} \mathrm{b}_{ \pm 68.5}$ & $560.9^{\mathrm{a}} \pm 38.1$ \\
& $42 \mathrm{~d}$ & $971.6 \pm 94.7$ & $979.8 \pm 106.6$ & $988.7 \pm 108.4$ & $1029.9 \pm 121.5$ \\
Feed : gain $(\mathrm{g}: \mathrm{g})$ & 1 to $42 \mathrm{~d}$ & $1.87^{\mathrm{a}} \pm 0.04$ & $1.80^{\mathrm{a}} \pm 0.04$ & $1.97^{\mathrm{b}} \pm 0.05$ & $1.96^{\mathrm{b}} \pm 0.05$ \\
Total mortality $(\%)$ & 1 to $42 \mathrm{~d}$ & 8.3 & 6.7 & 16.7 & 3.3 \\
\hline
\end{tabular}

a-b Mean values within a row having different superscripts are significantly different $(P<0.05)$

${ }^{1}$ A: 2.0\% DBT-treatment, treated with CY and supplemented with 2.0\% DBT; B: 0.5\% DBT-treatment, treated with CY and supplemented with 0.5\% DBT; C: CY-control, treated with $\mathrm{CY}$ and no medication; D: normal group, no $\mathrm{CY}$ and no medication. 
The effects of DBT on serum levels of IL-2 and IL-6 in chicks are shown in Figure 3 and Figure 4. In general, both the highest levels of IL-2 and IL-6 in the 4 groups and lowest levels of IL-2 and IL- 6 were observed at $28 \mathrm{~d}$ of age and at $14 \mathrm{~d}$ of age, respectively. At $14 \mathrm{~d}$ and $28 \mathrm{~d}$ of age, the levels of IL-2 and IL-6 were higher $(\mathrm{P}<0.05)$ in groups $\mathrm{A}$ and $\mathrm{B}$ than group $\mathrm{C}$. At $\mathrm{d}$ 28 of age, the levels of IL- 2 and IL- 6 were higher $(P<0.05)$ in groups A and B than group D. At $42 \mathrm{~d}$ of age, there was no difference in IL- 2 and IL- 6 production among the 4 groups.

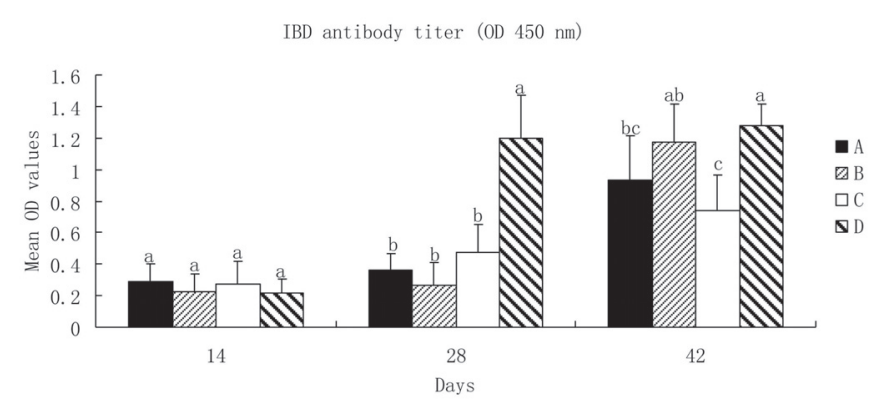

Figure 2. Effects of DBT on infectious bursal disease (IBD) antibody titer in chickens

a-c Within the same day, bars with different letters ( $a, b$ and $c$ ) differ significantly $(P<0.05) . n=20$. Chicks in all groups received live infectious bursal disease vaccine (IBDV, Strain D-78, Bestar Laboratories Singapore Pte. Ltd.) at $14 \mathrm{~d}$ of age. ELISA antibody titers (means \pm SD) measured from blood samples collected at 14 $\mathrm{d}, 28 \mathrm{~d}$ and $42 \mathrm{~d}$ of age.

${ }^{1} \mathrm{~A}$ : $2.0 \%$ DBT-treatment, treated with $\mathrm{CY}$ and supplemented with $2.0 \%$ DBT; B: $0.5 \%$ DBT-treatment, treated with $\mathrm{CY}$ and supplemented with $0.5 \% \mathrm{DBT}$; C: $\mathrm{CY}$-control, treated with $\mathrm{CY}$ and no medication; D: normal group, no $\mathrm{CY}$ and no medication.

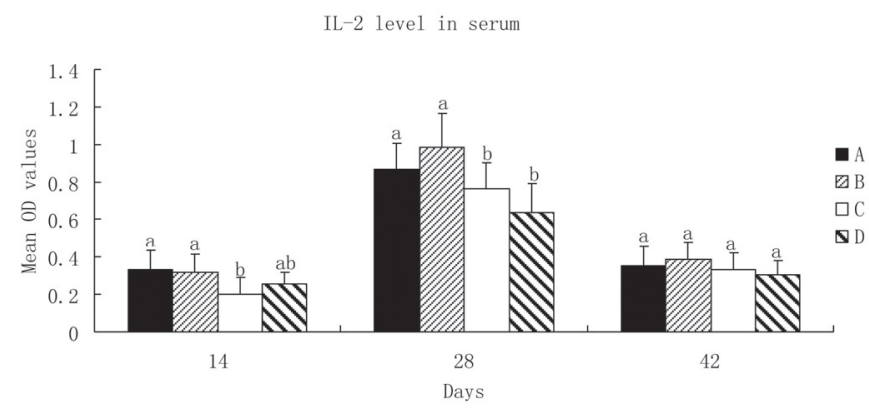

Figure 3. Effects of DBT on serum interliukin-2 (IL-2) level in chicks ${ }^{1}$

$\mathrm{a}, \mathrm{b}$ Within the same day, bars with different letters $(\mathrm{a}, \mathrm{b})$ differ significantly $(P<0.05) . n=20$. Results are expressed means \pm SD. At $14 \mathrm{~d}$ of age, levels of IL-2 in group A and B were significantly higher than that of group $C$, no significant difference was observed between group C and D. At $28 \mathrm{~d}$ of age, levels of IL-2 in group A and $B$ were significantly higher than those of group $C$ and $D$. No significant difference in IL-2 was observed among 4 groups at $42 \mathrm{~d}$ of age. Serum level of IL-2 was measured using the ELISA Kit.

${ }^{1} \mathrm{~A}$ : $2.0 \%$ DBT-treatment, treated with $\mathrm{CY}$ and supplemented with $2.0 \%$ DBT; B: $0.5 \%$ DBT-treatment, treated with $\mathrm{CY}$ and supplemented with $0.5 \% \mathrm{DBT}$; C: $\mathrm{CY}$-control, treated with $\mathrm{CY}$ and no medication; D: normal group, no $\mathrm{CY}$ and no medication.
Peripheral blood lymphocyte response to ConA is shown in Figure 5.

At $14 \mathrm{~d}$ and $28 \mathrm{~d}$ of age, significantly higher lymphocyte proliferative response to Con $\mathrm{A}$ was recoded in group $\mathrm{A}$ and $\mathrm{B}$ $(\mathrm{P}<0.05)$ than group $\mathrm{C}$ and $\mathrm{D}$. At $42 \mathrm{~d}$ of age, group $\mathrm{A}, \mathrm{B}$ and

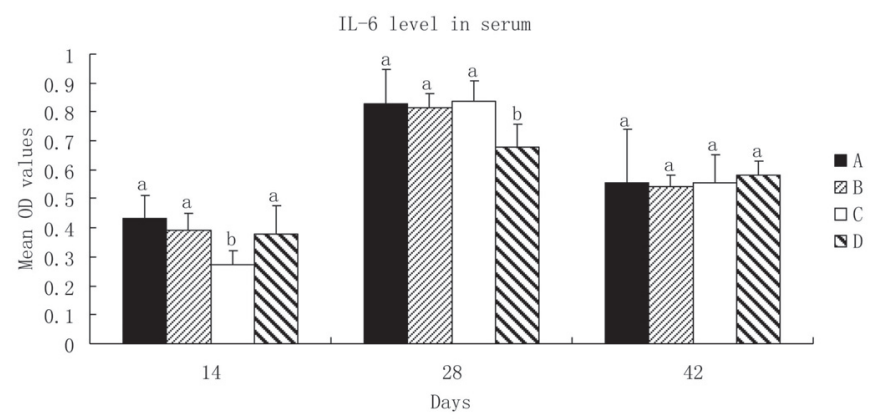

Figure 4. Effects of DBT on serum interliukin-6 (IL-6) level in chicks $^{1}$

$\mathrm{a}, \mathrm{b}$ Within the same day, bars with different letters (a, b) differ significantly $(P<0.05) . n=20$. Results are expressed means $\pm S D$. At $14 \mathrm{~d}$ of age, levels of IL- 6 in group A, B and D were significantly higher than that of group C. At $28 \mathrm{~d}$ of age, levels of IL-6 in group A, B and C were significantly higher than that of group D. No significant difference of IL- 6 was observed among 4 groups at $42 \mathrm{~d}$ of age. Serum level of IL- 6 was measured using the ELISA Kit. ${ }^{1} \mathrm{~A}$ : $2.0 \%$ DBT-treatment, treated with $\mathrm{CY}$ and supplemented with $2.0 \%$ DBT; B: $0.5 \%$ DBT-treatment, treated with $\mathrm{CY}$ and supplemented with $0.5 \% \mathrm{DBT}$; C: $\mathrm{CY}$-control, treated with $\mathrm{CY}$ and no medication; D: normal group, no $\mathrm{CY}$ and no medication.

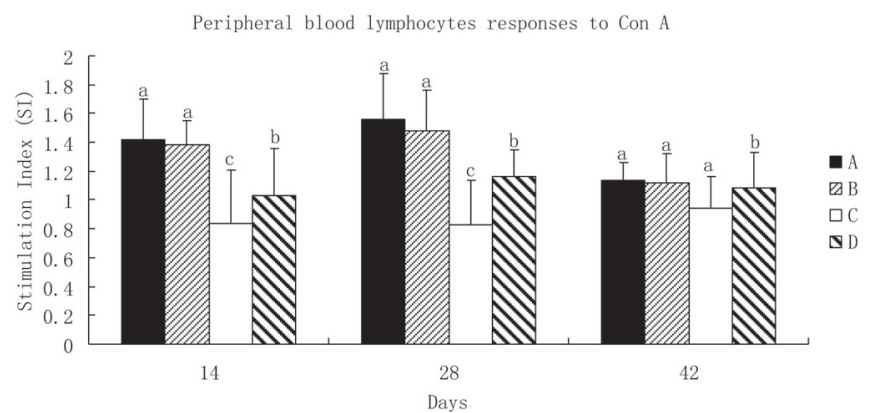

Figure 5. Effects of DBT on peripheral blood lymphocytes responses to concanavalin $A$ (ConA) in chicks ${ }^{1}$

a-c Within the same day, bars with different letters ( $a, b$ and $c$ ) differ significantly $(P<0.05) . n=20$. Results are expressed means \pm SD. The peripheral blood lymphocyte proliferation response to Con A was conducted by MTT assay at 14,28 , and $42 \mathrm{~d}$ of age. Significantly higher lymphocyte proliferative response to ConA was found in group $A$ and $B(P<0.05)$ than that of group $C$ (at 14, 28 and $42 \mathrm{~d}$ of age) and group $\mathrm{D}$ (at 14 and $28 \mathrm{~d}$ of age), whereas group $D$ had higher $(P<0.05)$ response to Con $A$ than group $C$ at 14 and $28 \mathrm{~d}$ of age.

${ }^{1} \mathrm{~A}$ : $2.0 \%$ DBT-treatment, treated with $\mathrm{CY}$ and supplemented with $2.0 \%$ DBT; B: $0.5 \%$ DBT-treatment, treated with $\mathrm{CY}$ and supplemented with $0.5 \% \mathrm{DBT}$; C: $\mathrm{CY}$-control, treated with $\mathrm{CY}$ and no medication; D: normal group, no $\mathrm{CY}$ and no medication. 
D had significantly higher lymphocyte proliferative response to ConA than group C (Figure 5).

\section{DISCUSSION}

It has been previously reported that cyclophosphamide treatment in the newly hatched period leads in chicks to a severe and permanent deficiency both in humoral immunity and cellular immunity (Toivanen et al., 1971; Muroga et al., 2005). This treatment is widely used to establish an immunosuppressive model and to investigate the function of the avian immunity system (Pink et al., 1985; Wilson and Boyd 1990; Honjo and Hirota, 1993). In our study, the immunosuppressive model of broiler chicks was established successfully and the effects of DBT on immunity and growth performance were observed.

In the present study, BW gain of chicks in 3 immunosuppressed groups (group A, B and C) significantly decreased compared with that of the normal group (group D). This result was consistent with previous studies, which reported that chicks treated with cyclophosphamide are inferior in growth performance to normal chicks (Toivanen et al., 1971; Muroga et al., 2005). Although BW gain was not improved by supplementation with DBT, the lower $(\mathrm{P}<0.05)$ FGR in both levels of DBT-treatment compared to that of the CY-control and normal groups, was exciting. This property indicates that DBT may be applied as a potential growth promotor. On the other hand, lower mortality in DBT-treated chicks may be attributed to the beneficial pharmacological properties of DBT.

Immune tissue development can in some cases reflect immune system response and functionality. In the present study, all chicks treated with $\mathrm{CY}$ had a significant decrease in bursa of Fabricius relative weight. This result was consistent with other studies, which reported that cyclophosphamide treatment in the newly hatched period in chicks leads to a severe and long-term deficiency in the development of the bursa of Fabricius (Toivanen et al., 1971; Muroga et al., 2005). However, after $28 \mathrm{~d}$ of age, the spleen enlargement in DBT-treatments was accompanied by the same tendency of IBD and ND antibody responses. These results indicated that DBT alleviated the spleen impairment caused by cyclophosphamide. Similar results were described by Yu F. (2009), who reported that Angelica sinensis polysaccharide, which is a major active component of DBT, remarkably increased the levels of liver index, thymus index and spleen index in immunosuppressed mice.

In poultry production, vaccines have been shown to provoke poor immune responses due to occasional vaccination failure (Liu et al., 2008). Improving the effectiveness of vaccines is an important issue. In the present study, although cyclophosphamide usually results in an immunosuppressive effect on immune response generated from ND vaccination (Munir et al., 2007), the ND antibody titers gradually decreased in all groups from the first vaccination to $28 \mathrm{~d}$ of age, strongly suggesting a risk that vaccination would fail. On the other hand, although the antibody in chicks treated with CY was significantly decreased compared to normal chicks, the increase of IBD antibody level in all groups from $14 \mathrm{~d}$ to $42 \mathrm{~d}$ indicated that the immune response generated from live infectious bursal disease vaccine was successful after $14 \mathrm{~d}$ of age. Nevertheless, chicks supplemented with $0.5 \%$ of DBT had significantly higher $(\mathrm{p}<0.05)$ levels of both IBD antibody and ND antibody than those of the CY-control at $42 \mathrm{~d}$ of age, indicating that DBT can enhance the humoral immunity response in immunisuppressed chicks.

In addition to humoral responses, cellular immunity plays an important role in fighting virus infections (Erf, 2004). In the present study, cellular immunity was evaluated by peripheral blood lymphocyte proliferation and serum IL-2 and IL-6 production. Our results revealed that the highest levels of IL- 2 and IL- 6 in all groups were at $28 \mathrm{~d}$ of age and the levels of IL- 2 and IL- 6 decreased at $42 \mathrm{~d}$ of age, but were still higher than those at $14 \mathrm{~d}$ of age. These changes of IL-2 and IL- 6 were closely related to the vaccination program. As is well known, both the humoral immunity response and the cellular immunity response were activated when chicks were vaccinated with live virus vaccine. In our study, chicks received live infectious bursal disease vaccine at the $14 \mathrm{~d}$ of age, then the cellular immunity response was activated and the production of cytokine, both IL-2 and IL-6, increased from $7 \mathrm{~d}$ post-vaccination (14 d of age, data not shown) to $14 \mathrm{~d}$ post-vaccination ( $28 \mathrm{~d}$ of age). The IL- 2 and IL- 6 in all groups decreased at $42 \mathrm{~d}$ of age, since the cellular immunity responses to the live virus vaccine were gradually attenuated. The most remarkable finding reported in the present study is the demonstration that supplementing with DBT markedly induced the production of IL-2 and IL-6. This result was consistent with previous studies, which have verified that application of DBT markedly induces cell proliferation, release of interleukin-2, -6 and -10, as well as phosphorylation of extracellular signal-regulated kinases (Gao et al., 2006; Gao et al., 2007). IL-2 is a Th-1-associated anti-inflammatory cytokine that plays a central role in cell-mediated immunity. IL-6 is an important proinflammatory cytokine required for the initiation and regulation of humoral immunity through the differentiation of naive T cells into Th-2 cells, which is associated with antibody production (Erf, 2004). Maroufyan et al., (2012) reported that IL-2 can facilitate immunoglobulin production. Therefore, the increase in IBD and ND antibodies in DBT-treatments may be attributed to the increase in IL-2 and IL- 6 production.

The Lymphocyte proliferation assay is widely used to evaluate cell-mediated immune response in normal and diseased states in chicks. ConA is known to stimulate T-cell proliferation. In the present study, a significantly higher (P $<0.05)$ lymphocyte proliferative response to ConA in DBTtreated groups indicates that enhanced cellular immunity response would be the major function of DBT regulating immunity. Our results were consistent with those obtained by Cao et al., (2010) and Gao et al., (2007), who reported that DBT could stimulate proliferation of the splenocytes and upregulate IFN-gamma, IL-2 and IL-6 mRNA expressions in splenocytes.

In conclusion, DBT was tested as an immunomodulator for the effect on BW gain, FGR, relative immunity, organ weight, and various parameters of immunity. Our results suggest that DBT not only significantly decreased feed:gain ratios and the mortality, but also enhanced cellular modulator immune and humoral immune responses in immunosuppressive chicks as well. DBT may be applied as an immunity enhancer in the poultry industry.

\section{ACKNOWLEDGMENTS}

This study was financially supported by Sichuan Animal Science Academy (SASA2009YZ008). 


\section{REFERENCES}

CHOI RC, GAO QT, CHEUNG AW, ZHU JT, LAU FT, LI J, LI WZ, CHU GK, DUAN R, CHEUNG JK, DING AW, ZHAO KJ, DONG TT, TSIM KW (2011) A Chinese Herbal Decoction, Danggui Buxue Tang, Stimulates Proliferation, Differentiation and Gene Expression of Cultured Osteosarcoma Cells: Genomic Approach to Reveal Specific Gene Activation. Evid-based Compl Alt 2011: 307548.

DIARRASSOUBA F, DIARRA MS, BACH S, DELAQUIS P, PRITCHARD J, TOPP E, SKURA BJ (2007) Antibiotic resistance and virulence genes in commensal Escherichia coli and Salmonella isolated from commercial broiler chicks farms. J Food Prot 70:1316-1327.

DONG TT, ZHAO KJ, GAO QT, JI ZN, ZHU TT, LI J, DUAN R, CHEUNG AW, TSIM KW (2006) Chemical and biological assessment of a Chinese herbal decoction containing Radix Astragali and Radix Angelicae Sinensis: determination of drug ratio in having optimized properties. J Agric Food Chem 54: 2767-2774.

ERF GF (2004) Cell-Mediated Immunity in Poultry. Poult Sci 83:580-590

FRITSCHE KL, CASSITY NA, HUANG SC (1991) Effect of dietary fat source on antibody production and lymphocyte proliferation in chickss. Poult Sci 70:611-617.

GAO QT, CHEUNG JK, LI J, CHU GK, DUAN R, CHEUNG AW, ZHAO KJ, DONG TTX, TSIM KWK (2006) A Chinese herbal decoction, Danggui Buxue Tang, prepared from Radix Astragali and Radix Angelicae Sinensis stimulates the immune responses. Planta Med 72:1227-1231.

GAO QT, CHEUNG JK, LI J, JIANG ZY, CHU GK, DUAN R, CHEUNG AW, ZHAO KI, CHOI RC, DONG TT, TSIM KW (2007). A Chinese herbal decoction, Danggui Buxue Tang, activates extracellular signal-regulated kinase in cultured T-lymphocytes. FEBS Lett 581:5087-5093.

HAN AY, ZHANG MH, ZUO XL, ZHENG SS, ZHAO CF, FENG JH, CHENG C (2010) Effect of acute heat stress on calcium concentration, proliferation, cell cycle, and interleukin-2 production in splenic lymphocytes from broiler chickss. Poult Sci 89: 2063-2070.

HONJO Y, HIROTAY (1993) Immunohistochemical Investigations of Lymphoscytes in the Lymphoid Organs of Cyclophosphamide Treated Chickss. J Vet Med Sci 55: 895-897.

HERNÁNDEZ F, MADRID J, GARCÍA V, ORENGO J, MEGÍAS MD (2004) Influence of two plant extracts on broilers performance, digestibility, and digestive organ size. Poult Sci 83:169-174.

HOERR FJ (2010) Clinical aspects of immunosuppression in poultry. Avian Dis 54: 2-15.

HSIEH CC, LIN WC, LEE MR, HSU SL, LIU HS, KAO ST, AND HSIEH MT (2003) Dang-Gui-Bu-Xue-Tang modulated the immunity of tumor bearing mice. Immunopharm Immunot 25:259-271.
LIU RS, XUE ZL, ZHANG SB, WANG BH (2008) Adjuvant effect of Chinese retard compound medicine on the immune response to ND vaccination. Chin J Vet Med 44:27-28.

LIU Y, ZHANG HG, LI XH (2011) A Chinese Herbal Decoction, Danggui Buxue Tang, Improves Chronic Fatigue Syndrome Induced by Food Restriction and Forced Swimming in Rats. Phytother Res 25:1825-1832.

MAROUFYAN E, KASIM A, EBRAHIMI M, LOH TC, BEJO MH, ZERIHUN H, HOSSENI F, GOH YM, FARJAM AS (2012) Omega-3 polyunsaturated fatty acids enrichment alters performance and immune response in infectious bursal disease challenged broilers. Lipids in Health and Disease 11:15.

MUNIR K, MUNEER MA, TIWARI A, CHAUDHRY RM, MURUGANANDAN S (2007) Effects of polyether ionophores on the protective immune responses of broiler chickss against Angara disease and Newcastle disease viruses. Vet Res Commun 31:909-929.

MUNIR K, MUNEER MA, MASAOUD E, TIWARI A, MAHMUD A CHAUDHRY RM, RASHID A (2009) Dietary arginine stimulates humoral and cell-mediated immunity in chickss vaccinated and challenged against hydropericardium syndrome virus. Poul Sci 88:16291638.

NING L, CHEN CX, JIN RM, WU YP, ZHANG HG, SUN CL, SONG CQ, HU ZB (2002) Effect of components of Danggui Buxue decoction on hematopenia. Chin J Chin Mater Med 27:50-52.

WILLIS WL, ISIKHUEMHEN OS, IBRAHIM SA (2007) Performance Assessment of Broiler Chickss Given Mushroom Extract Alone or in Combination with Probiotics. Poul Sci 86: 1856-1860.

YARRU LP, SETTIVARI RS, GOWDA NKS, ANTONIOU E, LEDOUX DR, ROTTINGHAUS GE (2009) Effects of turmeric (Curcuma longa) on the expression of hepatic genes associated with biotransformation, antioxidant, and immune systems in broiler chicks fed aflatoxin. Poult Sci 88: 2620-2627.

YU F. (2009) protective effects of angelica sinensis polysaccharide on immunological liver injury induced by concanavalin A in mice. Zhong Yao Cai 32:1580-1583. (Article in Chinese)

ZHANG YW, XIE D, XIA B, ZHEN RT, LIU IM, CHENG JT (2006) Suppression of transforming growth factor- $\beta 1$ gene expression by danggui buxue tang, a traditional Chinese herbal preparation, in retarding the progress of renal damage in streptozotocin-induced diabetic rats. Horm Metab Res 38:82-88.

ZHENG KY, CHOI RC, CHEUNG AW, GUO AJ, BI CW, ZHU KY, FU Q DU Y, ZHANG WL, ZHAN JY, DUAN R, LAU DT, DONG TT, TSIM KW (2011) Flavonoids from Radix Astragali induce the expression of erythropoietin in cultured cells: a signaling mediated via the accumulation of hypoxia-inducible factor-1 $\alpha$. J Agric Food Chem 59:1697-1704. 